\title{
La primera comunicación sobre rabia en Chile por el cirujano de la Armada don Pedro Videla Órdenes
}

\author{
ENRIQUE LAVALR.
}

\author{
The first report about Rabies in Chile by the Army surgeon \\ Mr. Pedro Videla Ordenes
}

Hace algún tiempo revisando documentos en la Biblioteca del Museo Nacional de la Medicina, encontré las tesis manuscritas de Licenciados en Medicina y Farmacia, de varios futuros médicos del siglo XIX. Me interesó la de don Pedro Videla Órdenes sobre la rabia. Posteriormente, bajo el título de "Memoria leída por Pedro Regalado $2^{\circ}$ Videla al graduarse de Licenciado en la Facultad de Medicina y Farmacia", la hallé finamente publicada en la Breve Historia de la Medicina en Chile, del doctor Sergio De Tezanos Pinto y comprobé, luego de consultar minuciosamente la literatura nacional a mi alcance, que la dicha memoria, constituía la primera comunicación sobre la rabia en Chile. ${ }^{1}$

Con motivo de la iniciación del conflicto bélico entre Chile y Bolivia, en febrero de 1879, con la ocupación de Antofagasta por la Armada chilena y el desarrollo posterior de la campaña, los estudiantes de Medicina se movilizaron "ofreciendo su apoyo y participación al Gobierno para la atención de los heridos", determinación que se tomó en una reunión pública realizada el 6 de marzo de aquel año, en el anfiteatro de la Escuela. Se formó una comisión presidida por el Decano Profesor Wenceslao Díaz, con dicho objeto, en la que participaron profesores y alumnos. Entre estos últimos estaba don Pedro Videla Ordenes ${ }^{2}$.

Había nacido Pedro Videla el año 1855, en Andacollo. Fueron sus padres don Pedro Regalado Videla y doña Pastoriza Órdenes. Por lo tanto, fue bautizado como Pedro Regalado $2^{\circ}$, realizando sus estudios secundarios en el Liceo de La Serena, donde estuvo hasta 1871. Cuando contaba con 16 años, se vino a la capital a graduarse de Bachiller en la Facultad de Filosofía y Humanidades, comenzando sus estudios de Medicina, los que terminó el 14 de abril de 1879, recibiendo el diploma de Licenciado en Medicina y Farmacia. Para satisfacer sus necesidades de estudiante de provincia, obtuvo la plaza de Inspector de Externos en el Instituto Nacional, que sirvió durante seis años.

Don Enrique Nercasseau y Morán, escribió en El Ferrocarril del 4 de junio de 1879, que Pedro Videla "era franco, vivo, de porte arrogante y delgado". ${ }^{3}$

El día 3 de marzo de 1879, en Valparaíso, el Ministro de la Guerra, don Eulogio Altamirano, oficiaba al
Decano de la Facultad de Medicina. doctor Wenceslao Díaz Gallegos, que "necesitándose tres cirujanos para el servicio del los buques Esmeralda, Magallanes y Covadonga, y habiéndome informado el Cirujano mayor del Departamento que no se encuentra en este puerto personas competentes que pueda proponer para aquellos empleos, por indicación del mismo Cirujano Mayor, solicito su colaboración para satisfacer la necesidad que se experimentó., Si no hubiera en esa capital médicos recibidos que quisieran aceptar los empleos de los que se trata, podrían proveerse de los estudiantes de Medicina más aventajados que eligiera Ud., pudiendo asegurárseles el rango y sueldo de Cirujano de la $1^{a}$ Clase".

Así Pedro Regalado $2^{\circ}$ Videla Órdenes fue nombrado Cirujano $1^{\circ}$ de la Armada para ser embarcado en la Corbeta Covadonga, poco antes de leer su tesis ya mencionada a la Comisión de la Facultad, obteniendo el grado de Licenciado en Medicina y Farmacia, el 14 de abril de $1879 .{ }^{1}$

Recordemos que sólo seis años después, en julio de 1885, Pasteur utilizó por primera vez inyecciones múltiples de una suspensión preparada a partir de la médula espinal de un conejo, infectada y desecada, que contenía una cantidad variable de virus de la rabia vivo, en el joven Joseph Meister, mordido por un perro rabioso, quien recibió 13 inoculaciones practicadas por el doctor Granche. El segundo caso fue el del pastor Jupille y el 26 de octubre de aquel año, Pasteur anunció el éxito de los dos tratamientos en una memorable comunicación a la Academia de Ciencias de Francia, que marcaba el trascendental acontecimiento de la iniciación de la vacunación antirrábica. ${ }^{4,5}$

Pedro Videla manifiesta, en primer lugar, que "el motivo que me sugirió la idea de escribir sobre la rabia, fue el haber presenciado en las vacaciones del año anterior un caso de esta terrible enfermedad. Posteriormente, dos enfermeros que se presentaron en el Hospital San Juan de Dios, atacados del mismo mal, me decidieron a llevar a efecto mi resolución". A continuación detalla el orden que ha empleado en la elaboración de su trabajo: "el método que he seguido es el siguiente: trato en primer lugar, de la rabia en jeneral $i$ de las diversas teo- 
rías que se han emitido acerca de la naturaleza, de las analojías $i$ diferencias en las manifestaciones sintomáticas que existen entre la rabia del hombre $y$ de los animales; de los diversos tratamientos que se han empleado para combatirla y finalmente apuntar el medicamento cuya acción fisiolójica puede explicar las prácticas del pueblo, que considera segurísima la acción del Datura stramonium (chamico,) en la curación de la rabia. Como creo que nada se ha dicho sobre esto hasta ahora entre nosotros, he escrito estos apuntes".

Afirma que "esta enfermedad es enteramente orijnaría de los animales $i$ el hombre solo la contrae por la inoculación del virus rábico. La naturaleza de este virus, como la de todos los de su especie, nos es desconocida por completa i el microscopio no ha podido revelárnosla".

En aquella época se hablaba de enfermos en que se había desarrollado espontáneamente la rabia y Pedro Videla, escogiendo la opinión del célebre clínico francés Jaccoud, asegura que "es el resultado de mala observación, pues entonces se ha confundido el síntoma hidrofobia, que es el más característico de esta afección con la hidrofóbia esencial, que puede desarrollarse con una enfermedad aislada e independiente, o bien como sintomática de una neurosis general, como el tétanos i el histérico".

Enseguida, Pedro Videla expone otras hipótesis patogénicas, mencionando al médico italiano Schivardi, "quien apoyándose en la observación de un caso en que los primeros síntomas desaparecieron por el tratamiento de la electricidad, para dar lugar a continuación a fenómenos enteramente análogos a los de la intoxicación urémica, emitiendo la opinión, recojida por Jaccoud, de que los síntomas siguientes observados en la rabia eran debido al envenenamiento de la sangre por la urea o por el carbonato de amonio". Prosigue con que "una segunda hipótesis es la de que el virus produce en el organismo una neurosis tóxica análoga a la del envenenamiento por la estricnina o que se puede comparar a la eclampsia de las mujeres embarazadas".

También está la opinión de los antiguos "que creían que la rabia se desarrollaba gracias al influjo que ejercía sobre el organismo cierto animalillo que se criaba bajo la lengua de los perros i que se denominaba Ascaris vermicularis lingualis". Por último, dice Pedro Videla, "la teoría que me parece más racional, es la emitida por el doctor Sáenz, guatemalteco, en el trabajo presentado a la Facultad de Medicina de Paris $i$ que según ella, el virus, cuyos elementos existen en todos los animales $i$ en el hombre de un modo latente $i$ cuya presencia no puede demostrarse ni químicamente ni con el auxilio del microscopio, necesita para manifestarse en los animales de ciertas condiciones físicas o químicas, como el hambre, la sed, el calor, el celo; $i$ el hombre de la inoculación i además de cierta predisposición de la economía o receptividad propia de cada individuo, pues no todas las personas mordidas por perros rabiosos contraen la enfermedad".
Todo esto lleva al joven licenciado Videla señalar diferencias sobre la frecuencia de la aparición de la enfermedad en ciertos lugares, afirmando que es más común en Suecia, Noruega, Dinamarca, según lo señalado en el tratado de Higiene Pública de Monlau, así como en Chile cree "que en la provincia de Coquimbo, especialmente en el lugar de Andacollo, los casos de este terrible mal, son relativamente numerosos, comparándolos con los que dejan conocer en Santiago, donde sólo he visto tres casos, en el tiempo que he residido en ella".

Por otra parte, es necesario destacar que el cuadro clínico de la rabia en el hombre y en el perro, descrito por Pedro Videla, es de una minuciosidad excelente y envidiable, pudiendo integrar cualquier tratado actual sobre la enfermedad. "Por no alargar este trabajo i no fatigar a la comisión que me escucha, me he limitado a hacer un simple bosquejo", aclara Pedro Videla con toda modestia.

¿Qué tratamiento recibían los enfermos de rabia en esa época?. Dice Videla: "como he visto tres casos de ella $i$ habiendo sido en todos ellos distinto el tratamiento, es natural que no deduzca una conclusión rigurosa $i$ necesaria $i$ únicamente una mera hipótesis sin más alcance que una posibilidad. El tratamiento se divide en preventivo $i$ curativo. Para el primero son los cáusticos i entre ellos el hierro enrojecido i los distintos cáusticos minerales, como el sublimado corrosivo, los ácidos fuertes, el cloruro de zinc, el nitrato de plata, etc. Antes de su empleo sería útil precaución emplear lociones con agua avínagrada sobre la herida, ventosas secas que atraigan el virus rábico al exterior. La compresión circular de la pierna que impide que el virus entre a la circulación, también es un buen procedimiento. Si todo esto no ha producido resultado es necesario proceder a atacar directamente la enfermedad que ya hace sus manifestaciones", según lo expresa el autor y recuerda "que la multitud de medicamentos que se han empleado en el tratamiento de esta enfermedad prueban su ineficacia".

Señala, como lo menciona el doctor Sáenz, "que antiguamente se arrojaba al mar a los rabiosos hasta provocar en ellos síntomas de asfixia por sumersión i agrega que el poeta Eurípides fue curado por este mismo método, En Quesaltenango, pueblo de Guatemala, entierran hasta el cuello a los rabiosos i el mismo procedimiento emplean en Ámsterdam, donde cuenta con muchísimos partidarios".

Entre los remedios "que han gozado de mucha aceptación $i$ hai uno que es citado por varios autores $i$ pertenece a Van Swieten, es el siguiente:

almizcle 16 gramos

cinabrio nativo 20 gramos

cinabrio artificial 20 gramos

Se reducía esto a polvo i se administraba por cucharadas en una de alcohol.

Los antiespasmódicos minerales como el óxido de zinc $i$ vejetales como la valeriana, tampoco han producido ningún resultado. Otro tanto ha sucedido con los narcóticos como el opio i el cloral". 
En uno de los enfermos mencionados por Pedro Videla, se utilizó Datura stramonium "i aún cuando el resultado fue fatal, como los otros que he visto, puedo asegurar que mediante el empleo de este medicamento, el enfermo no solo tuvo momentos de calma $i$ tranquilidad, sino que alcanzó a pasar el término de cuatro días que, como plazo fatal, fijan los autores como término del mal. Recuerdo perfectamente que la abundante salivación que tenía el enfermo, disminuyó considerablemente con el remedio i de ahí que los accesos convulsivos provocados por la acumulación de saliva en la garganta $i$ que traen al enfermo el recuerdo aborrecido del agua, también calmaron su intensidad".

Justamente, una de las conclusiones más importantes de la tesis de Pedro Videla es que "el Datura stramonium puede, si no curar, por lo menos aliviar los síntomas más molestos de la enfermedad. Es un estupefaciente que en virtud de la acción propia de esta clase de medicamentos, puede calmar y disminuir la acción excitante de los centros nerviosos producidos por el virus rábico". ${ }^{1}$

El día 21 de mayo de 1879, en la rada de Iquique, la tranquilidad aparente que parecía existir en los buques chilenos que bloqueaban el puerto, la Esmeralda y la Covadonga, fue interrumpida por la llegada de los blindados peruanos, el Huáscar y la Independencia. Carlos Condell, comandante de la Covadonga, enfiló proa hacia aguas más bajas al sur de Iquique, siendo perseguido por la Independencia. Pedro Videla, como cirujano de aquella corbeta, segura- mente se aprestaba a atender con todo su talento y fuerzas a los que resultaran heridos, pero un proyectil de 300 libras lanzado a la Covadonga por el monitor Huáscar, amputó sus dos piernas, falleciendo a las pocas horas por una hemorragia incoercible que nadie pudo detener, ofrendando su vida por la patria. Como lo manifestó el Profesor Federico Puga Borne, al recordar que Pedro Videla "loco de alegría, después de ser nombrado cirujano de la marina, decía: me voy satisfecho y orgullos. Acabo de recibir también de mi padre permiso para morir". "Y la primera bala que el cañón peruano lanzó a la Covadonga verificó el presentimiento", ${ }^{6,7,8}$

\section{Bibliografía}

1.- De Tezanos P S. Breve Historia de la Medicina en Chile. Editorial Universidad de Valparaíso, Chile, 1995, p. 310 .

2.- Cruz-Coke M R. Historia de la Medicina Chilena. Editorial Andrés Bello, Santiago de Chile, 1995. p 399.

3.- El Ferrocarril. 4 de Junio de 1879.

4.- Mandell G L, Gordon D R, Bennett J E. Enfermedades Infecciosas. Principios y practica $3^{\circ}$ Edición, 1991. Tomo II. p. 1362.

5.- Laín Entralgo P. Historia Universal de la Medicina Tomo VI. p. 182. Ed. Salvat, Madrid, España. 1975.

6.- Bulnes G. Guerra del Pacífico. Tomo 1. p. 180 y 182. Editorial Del Pacífico SA, Santiago de Chile, 1955.

7.- Grez V. El Combate 1 Homérico. p. 56 - 83. Imprenta de la Patria, Valparaíso, Chile, 1880.

8.- Maffet H A. El Cuerpo Médico y la Medicina en Chile. Santiago de Chile, 1939 p. 362. 